\title{
Testing the Feasibility of a Nursing Intervention Focusing on Family Management for Caregivers of Children with Autism
}

\author{
Thi Lan Anh Mai, R.N., Ph.D. ${ }^{1}$, Nujjaree Chaimongkol, R.N., Ph.D. ${ }^{2}$ \\ ${ }^{1}$ Namdinh University of Nursing, Nam Dinh City, Nam Dinh 420000, Vietnam. \\ ${ }^{2}$ Faculty of Nursing, Burapha University, Mueang, Chon Buri 20131, Thailand. \\ Received 19 January 2021 • Revised 8 June 2021 • Accepted 10 June 2021 • Published online 27 July 2021
}

\begin{abstract}
:
Objective: This pilot study aimed to investigate the feasibility and effects of a nursing intervention focusing on family management for caregivers of children with autism.
\end{abstract}

Material and Methods: Five primary caregivers of children with autism, who visited a hospital in Vietnam were recruited by convenience sampling. All participants were parents, with mean age of $33.40(+5.46)$ years, who attended weekly family-management intervention for four consecutive weeks. The intervention was adapted from the Building on Family Strengths program and guided by the Family Management Style Framework. The Beach Center Family Quality of Life Scale and the Caregiver's Strain Questionnaire were used to measure outcomes at three-point times, namely, baseline (week 0), post-intervention (week 4), and follow-up (week 8). Descriptive statistics and Friedman test were used in data analysis .

Results: The age of children with autism was from 4-8 years old ( $M=5.60)$. The findings revealed that the participants attended all implementation sessions without dropping out. Significant positive changes in the quality of family life and the burden of the caregivers were found among the participants after receiving the intervention.

Conclusion: The family-management intervention was feasible and beneficial to family caregivers of children with autism in Vietnam. Future studies should explore the effectiveness of this intervention in randomized controlled trials with a larger sample size. This intervention would be more appropriate as integral component in the services for family and children with autism.

Keywords: autism, burden, caregivers, children, family management, family quality of life

Contact: Assoc. Prof. Dr. Nujjaree Chaimongkol, R.N., Ph.D.

Faculty of Nursing, Burapha University, Mueang, Chon Buri 20131, Thailand.

E-mail: nujjaree@buu.ac.th

(c) 2021 JHSMR. Hosting by Prince of Songkla University. All rights reserved.

This is an open access article under the CC BY-NC-ND license

(http://www.jhsmr.org/index.php/jhsmr/about/editorialPolicies\#openAccessPolicy).
J Health Sci Med Res 2022;40(3):239-250 doi: 10.31584/jhsmr.2021830 www.jhsmr.org 


\section{Introduction}

Autism is a lifelong disability in social interaction, verbal and nonverbal communication, and restrictive and repetitive behaviors. In recent decades, studies have shown that the incidence of autism has increased rapidly. According to the Centers for Disease Control and Prevention in 2020, the prevalence rate of autism in the United States in 2016 was estimated at approximately one in 54 children aged 8 years. ${ }^{1}$ In Vietnam, research on prevalence of autism spectrum disorders among children aged 18-30 months showed that the number of children with autism in three cities and provinces was $0.7 \%{ }^{2,3}$ All of the children with autism in the study had problems in the areas of social communication and over $93.0 \%$ had disabilities in communication and speech quality, making adaptation difficult in their daily lives. About one half of children with autism exhibit behavior problems including anger, non-compliance, aggression, and self-injury. ${ }^{4-6}$ These behavioral problems result in families of children with autism playing a critical role in their child's ability to adapt-in daily life as well as in receiving treatments. By taking on various roles, families of autistic children report a high burden and low family quality of life., ${ }^{7,8}$ The adverse mental and physical effects on parents, if prolonged without any supportive intervention can re-impact on the autistic child's behavior, causing problems to worsen.

The intervention programs and their effectiveness are various depending on development level, health care system characteristics, and education level of family members. The importance of education interventions for families of autistic children cannot be overemphasized. Education intervention is associated with increased likelihood of mental health related quality of life, family functioning and child outcomes. ${ }^{9,10}$ The existing literature revealed that psychological interventions for parents of individuals with autism may lead to both decreased stress in parents, and improvements in child behavior. Therefore, intervention should focus on the psychological needs of families, especially after receiving their child's autism diagnosis. ${ }^{11-13}$ Technology-based interventions have proved that families of autistic children receive sufficient support, regardless of their geographical distance or a variety of other logistical difficulties with health care service systems. ${ }^{14,15}$ Additionally, other research revealed that social support interventions reduced mental health problems and other negative outcomes of families of children with autism. Various technical interventions were used to support family caregivers; however, the telephone was found to be valuable to support their psychological wellbeing. ${ }^{16}$

Kieckhefer and colleagues ${ }^{10}$ conducted a parent education intervention for parents of children with chronic health conditions who lacked adequate support. This research provided evidence that parent education intervention can improve five important outcomes for parents, consisting of parent's self-efficacy, coping, parent-child shared management, family quality of life and depressive symptoms. The program strengthens the parents' capacity to manage their own lives and the lives of their children living with a chronic illness in order to improve outcome variables. The parent education approaches may encourage focus on parent needs and include information needs, as well as emotional support. Moreover, the intervention provided methodological instructions to support children's conditions and help them adapt to everyday life. In particular, this program also provided parents with chronically ill children with the opportunity to share experience, learn from, and help other parents in similar circumstances to overcome difficulties. Participating in parent education classes helped improve the independence of parents to manage the situation of their children, as well as cope with and overcome the challenges that parents face when living with children on their own. The focus on parents and caregivers in coping 
with and managing their children's conditions, highlighted in the intervention program, has potential to partially be applied to manage caregivers of children with autism.

There is a relative lack of studies related to familymanagement interventions in Vietnam, and what families actually understand by quality of life, burden, and the impact of family-management on family quality of life, burden and continually caring for and living with an autistic child throughout their life., 2,17 Thus, this study aimed to develop and test the feasibility and effectiveness of the familymanagement intervention program with the expectation of improving family quality of life and lessening the burden of the family caregivers. Additionally, after conducting a feasibility study, the primary investigator (PI) had gained more experience in performing the intervention with participants to be utilized in a randomized controlled trial study in the future. Finally, the PI was able to adjust the data collection method to ensure the validity and reliability of the intervention program as well as the study measurements.

Knafl's Family Management Style Framework $(F M S F)^{18}$ is a conceptualization of the key elements of family members' efforts to manage a child's medical condition and incorporate it into daily living activities. For the purpose of our study, the context was a caregiver's perspective on autism in children and the resulting behavioral issues, causes, severity, and prognosis of the disruptive behaviors, difficulties and challenges in implementing treatment regimens, and the ability to manage children's behavioral difficulties effectively. Management of behaviors are efforts that family members undertake to cope with family interactions, and how families incorporate the challenges of living with a child with autism and behavioral management into their daily lives. The perceived consequences are the family's awareness of having children with autism in the family life. The family management style is the result of the responses of family members to these three components. The FMSF also includes family members' awareness of the factors that affect family life and their response to autism (social and cultural contexts). The family management style is conceptualized as a mediation of individual and family system outcomes. In our study, the family system outcomes were specifically defined as family quality of life and caregiver burden. ${ }^{18,19}$ Conceptual framework of the study is presented in the Figure 1.

This study aimed to determine the feasibility of the family-management intervention by comparing mean scores of family quality of life and caregiver burden among three-time measures of pre-intervention (week $0, T_{1}$ ), postintervention (week 4, $\mathrm{T}_{2}$ ) and follow-up 4-weeks after (week $\left.8, T_{3}\right)$ in which the changes in outcomes over time were also examined.

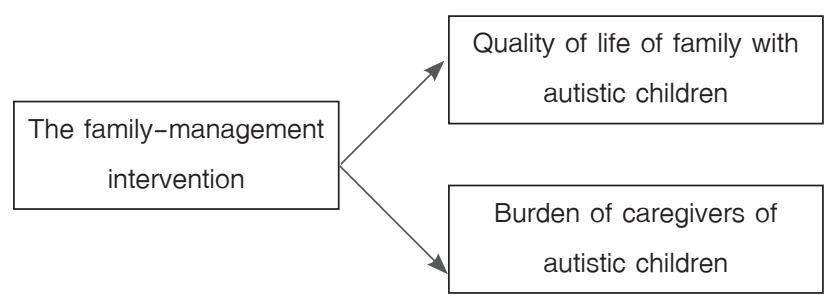

Figure 1 The conceptual framework of the study

\section{Material and Methods}

This study employed a one-group pretest-posttest design. The study plan was to recruit 5 participants who met the inclusion criteria for data collection as suggested for a pilot study. ${ }^{20}$ The implementation phase was conducted from November 2019 to February 2020.

The target population was the primary caregivers of children with autism who used the health services in an outpatient department at a tertiary children's hospital in Hanoi, Vietnam. Convenience sampling technique was used to recruit the participants from the target population to obtain five primary caregivers of children with autism spectrum who were representative of other members of 
their families. The inclusion criteria were primary caregivers who: had a biological relationship with the child, provided care to a child without receiving a wage or payment, lived in the same house with the child at least six months prior to data collection ${ }^{21}$, had the ability to read Vietnamese, and a willingness to participate in the study. Exclusion criteria were that the caregiver reported a serious physical or mental health problem and was unable to complete all sessions of the intervention.

This study was approved by Institutional Review Board (IRB) for Graduate Study, Faculty of Nursing, Burapha University, Thailand (\#02-04-2562), and the Ethics Committee of Vietnam National Children Hospital (\#VNCH-RICH-2019-61).

A demographic questionnaire was developed by the $\mathrm{PI}$ to record the following information: child's age, gender, number of siblings, duration since diagnosis, birth order, and the family caregiver's relationship to the child, gender, marital status, education, and occupation.

The Beach Center Family Quality of Life Scale was developed by Hoffman et al. ${ }^{22}$ It was used to measure family quality of life as perceived by the family caregivers of children with autism. The 25 -item scale has five domains (subscales) of family life: family interaction, parenting, emotional well-being, physical/material well-being, and disability-related support. Each item has 5-rating options on satisfaction response: 1 (very dissatisfied), 2 (disatisfied) 3 (neither), 4 (satisfied), and 5 (very satisfied). The scale takes 10 to 15 minutes to complete. The total summed scores range from 25 to 125. Each of the five subscales are also summed separately. Higher score indicates higher family quality of life. In this study, Cronbach's alpha reliability was 0.78 .

The Caregiver's Strain Questionnaire was developed by Brannan, Bickman and Heflinger. ${ }^{23}$ It was used to measure the perceived degree of burden related to the difficulties, strains, and other negative effects of caregiving. The 21-item scale contains five domains: employment, financial, physical, social, and time. Each item has 5-rating response options: 1 (not at all), 2 (a little), 3 (somewhat), 4 (quite a bit) and 5 (very much). Scores are summed and divided by 21 to provide a mean score. Higher the mean score indicates greater burden of providing care. The Caregiver's Strain Questionnaire has demonstrated good internal consistency reliability and validity. ${ }^{23}$ In our study, the Cronbach's alpha reliability was 0.82 .

Permission to use and translate the Beach Center Family Quality of Life Scale and the Caregiver's Strain Questionnaire was granted by the owners. The tools were translated into Vietnamese language using a backtranslation technique according to World Health Organization guidelines. ${ }^{24}$ The original questionnaires in English were independently translated into Vietnamese by two translators who were bilingual experts in both English and Vietnamese (Vietnamese English teachers in a University). The two Vietnamese versions from each translator was then compared and refined into one by the PI based on content of individual item agreement for their equivalence. A native Vietnamese-speaking translator who was expert in English language translated the final Vietnamese version back into English. The PI and the second author checked the backtranslated English version and the original English version for language accuracy and comparability of the contents as well as cultural appropriateness. This step was to ensure the scale content validity.

Cronbach's alpha reliability of the Beach Center Family Quality of Life Scale and the Caregiver's Strain Questionnaire were acceptable with values of 0.72 and 0.80 , respectively. Although the sample size in the study was relatively small, reliability depends on number of items rather than number of participants. ${ }^{25}$ 


\section{Development of the family-management inter-} vention

The family-management intervention was adapted from the Building on Family Strengths program guided by the FMSF and intensive review of relevant literature about intervention studies for families with autistic or chronically ill children. ${ }^{10,18,19}$ The family-management intervention was validated by 3 content experts including, a psychiatric pediatrician, a maternal-newborn nursing and midwifery instructor and a pediatric nursing instructor. The experts were asked to evaluate individual contents of the intervention as well as the entire intervention program. Evaluation appraised the relevance and appropriateness of individual contents in terms of the construct. The $\mathrm{PI}$ and the second author then revised content and other aspects of the intervention following the experts' comments and suggestions.

According to the policy of the National Hospital of Pediatrics, each child with autism, depending on the severity of symptoms, participates in the intervention program periods, each lasting four weeks. For the convenience of caregivers, to ensure full participation in the intervention program, instead of the eight face to face sessions in the original intervention, intervention protocol in this study included four-weekly face to face sessions and four-weekly phone-call support sessions from the PI.

From the FMSF, it suggested that family management differs from other family concepts, such as family functioning or family environment, in that it is specifically concerned with identifying the domains of condition management rather than being more general. ${ }^{19}$ As such, special attention in the intervention program was given to problem solving based on the caregiver's action plans. These action plans were developed at the end of sessions based on the provided knowledge and discussion on individual family issues encountered while living with an autism. For example, one session focused on problem solving related to emotional changes, while another session addressed problem solving related to changes in family relationships and family members' communication.

\section{The family-management intervention}

1. Program sessions. Four sessions lasting about 60 minutes each, were held once weekly and included five participants. The program included brief presentations by the PI with common foundations of knowledge related to autism and family management, structured parent discussions related to the topics, discussion of parent development and individualized action plans. Contents for the brief presentations were based on previously documented needs of caregivers of children with autism. The fourweekly session program was implemented to create action plans for the caregivers. The PI provided information and supported the caregivers in developing an action plan. At their homes, via a prearranged phone call, the caregivers were facilitated by the $\mathrm{PI}$ to perform the action plans. In the following session, the $\mathrm{PI}$ and caregivers discussed how the action plans were implemented and developed problemsolving strategies. Details of each session are presented in Table 1.

\section{The caregiver booklet}

The contents of the intervention program were included in a parent booklet with a schedule of the sessions, the contents of presentations, key class concepts, additional references, examples of successful strategies in managing children with autism, an action plan and evaluation form of caregiver's satisfaction of the family-management program. The booklet was given to the participants in session one and they were encouraged to use it at home, in the classes and after the completion of each session. Caregivers developed their own action plan at the end of every session. They then followed the action plan at home in conjuction with phone calls from the PI to discuss prolem-solving strategies based on the implementation of the action plans before the beginning of the following session. 
Table 1 The family-management intervention program contents, related theoretical-base and objectives

\begin{tabular}{|c|c|c|}
\hline Content & Theoretical framework & Objective \\
\hline $\begin{array}{l}\text { Session I: Introduction to the family- } \\
\text { management intervention } \\
\text { (60 minutes) }\end{array}$ & $\begin{array}{l}\text { Defining the situation are caregiver views } \\
\text { of child with autism and vulnerabilities; the } \\
\text { cause, seriousness and predictability of } \\
\text { autism; the difficulty of carrying out the } \\
\text { treatment regimen and their ability to } \\
\text { manage effectively which impact family } \\
\text { quality of life and burden of family with } \\
\text { autistic children. }{ }^{18,19,27}\end{array}$ & $\begin{array}{l}\text { Overview: the impact on family life of living } \\
\text { with a child on the autism spectrum; and } \\
\text { effective family-management strategies }\end{array}$ \\
\hline $\begin{array}{l}\text { Session II: Management of family } \\
\text { caregivers' emotional dimension and } \\
\text { the child's life ( } 60 \text { minutes) }\end{array}$ & $\begin{array}{l}\text { Management behaviors are efforts or } \\
\text { behaviors family members make to manage } \\
\text { autistic child and their own family problems; } \\
\text { how families incorporate condition } \\
\text { management into their everyday life. }\end{array}$ & $\begin{array}{l}\text { Explore how having a child with autism can } \\
\text { impact the family's emotions and coping } \\
\text { skills; how to support the child's skills in her/ } \\
\text { his daily life. }\end{array}$ \\
\hline $\begin{array}{l}\text { Session III: Supporting family rela- } \\
\text { tionships, family communications and } \\
\text { parenting ( } 60 \text { minutes) }\end{array}$ & $\begin{array}{l}\text { Management behaviors are how families } \\
\text { incorporate condition management into their } \\
\text { everyday life to enhance management } \\
\text { mindset and parental mutuality. }{ }^{18,19,26}\end{array}$ & $\begin{array}{l}\text { Support the impact of having a child with } \\
\text { autism on parents' relationships, family } \\
\text { communication, and parenting; manage the } \\
\text { impact using fundamental communication and } \\
\text { leadership skills. }\end{array}$ \\
\hline $\begin{array}{l}\text { Session IV: Finding available } \\
\text { resources and transitions into having } \\
\text { a meaningful life (60 minutes) }\end{array}$ & $\begin{array}{l}\text { Finding available resources and transitions } \\
\text { into having a meaningful life were important } \\
\text { for caregivers of autistic children; they direct } \\
\text { family focus and future expectations. }{ }^{18}\end{array}$ & $\begin{array}{l}\text { Support caregivers in obtaining support from } \\
\text { available resources; explore the process of } \\
\text { going through major life transitions into } \\
\text { having a meaningful life. }\end{array}$ \\
\hline
\end{tabular}

\section{The telephone logs}

The telephone logs for the PI and participants were developed and provided on the first day of the intervention. The logs were used to track progress and interactions with the participants. The PI called each caregiver every the day after each session. Based on the previous content presented and related behavior challenges, they answered five short questions about their action plan. For example, if the behavior was fine motor problem, participants needed to respond to "What will you do?", "When will you do it?", “How much will you do?", "How often will you do it?”, and "How confident are you in carrying out the action plan?"

\section{Procedures of the implementation}

After signing informed consent, the $\mathrm{Pl}$ made an appointment with the participants in regards to a telephone call for the baseline surveys. The PI interviewed the participants to complete the demographic information, the Beach Center Family Quality of Life Scale and the Caregiver's Strain Questionnaire by phone (week 0). This was the pre-test data (pre-test, $\mathrm{T}_{1}$ ). From day 1 of week 1 to week 4 , the participants received the intervention at the hospital, comprising the four-weekly session program designed for the caregivers to create action plans. Each session lasted about 60 minutes. At the end of each session, 
the $\mathrm{PI}$ and caregivers made an appointment for the follow up telephone calls. After completing the intervention, the PI interviewed the participants to complete the Beach Center Family Quality of Life Scale and the Caregiver's Strain Questionnaire (post-test; week 4, $\mathrm{T}_{2}$ ) and received feedback on participant satisfaction with the familymanagement intervention program. The $\mathrm{PI}$ and participants then scheduled the $T_{3}$ measurement. At the end of week 8 , the $\mathrm{PI}$ interviewed the participants to complete the Beach Center Family Quality of Life Scale and the Caregiver's Strain Questionnaire (follow-up, $T_{3}$ ). While conducting the pilot study, the research assistants also were trained to become familiar with instruments for data collection.

\section{Data analysis}

Data were analyzed by using $\mathrm{IBM}^{\circledR}$ SPSS $^{\circledR}$ version 26. The level of statistical significance was set at $p$-value $<0.050$. Descriptive statistics including frequencies, means, and standard deviations were used to describe the characteristics of the participants, children, and outcome variables. Friedman test was carried out to compare the mean scores for family quality of life and burden across three time points. The Dunn-Bonferroni pairwise comparison examined the differences of the outcome variables between each pair of times, which is recommended for statistical pairwise comparison of non-parametric repeated measure ANOVA. ${ }^{25}$

\section{Results}

Through screening, five participants in total were selected to participate in the study. All participants completed the research process, including completing four sessions of the intervention program and all three measurements. Through the feedback during the final session, participants indicated that they were satisfied with the family-management intervention program. The caregivers were mostly mothers $(80.0 \%)$ of children with autism. The mean age of the participants was 33.40 years $( \pm 5.46$, range $26.00-39.00)$. More than half of the participants $(60.0 \%)$ had high education level of university and above, and they all worked as officers. The mean age of the children was 5.60 years $( \pm 1.67$, range $4.00-8.00)$. They had been diagnosed with autism for 2.0 years $( \pm 1.23$, range 1.00-4.00), with only sleep disorders as comorbidities for all children. Most of the children (80.0\%) were boys and about half of them $(60.0 \%)$ were the first child in their family, while $40.0 \%$ were the second child. The severity of autistic-related behavioral problems in the study were moderate level.

All the total and subscale scores of family quality of life and burden of family caregivers were measured at the three-time points of: before beginning the intervention (T1); after the intervention at week 4 (T2); and at the follow-up at week 8 (T3). Table 2 presents the descriptive statistics; the differences of the total and subscale scores of family quality of life and burden of family caregivers between the three-time points and the different pairs. The Friedman test results showed participants' improvements after taking part in the family-management intervention. Moreover, the pairwise comparisons results of the DunnBonferroni post hoc tests were conducted to determine the differences between pairs of time measurements for both family quality of life and caregiver burden, and for the total and all subscale scores. There were significant differences in both total and subscales' scores of family quality of life and burden for at least one pair of the three-point times $(p-v a l u e<0.050)$. The findings indicated that after receiving the family-management intervention participants had better family quality of life and lower burden than pre-intervention. Details are shown in Table 2. 
Table 2 Comparisons of outcome variables at three-time measures by Friedman test

\begin{tabular}{|c|c|c|c|c|c|}
\hline Variable & Time & M (S.D.) & $\chi^{2}$ & df & $p$-value \\
\hline \multirow[t]{3}{*}{ Family quality of life } & 1 & $32.00(3.39)^{\mathrm{a}}$ & \multirow[t]{3}{*}{10.00} & \multirow[t]{3}{*}{2} & \multirow[t]{3}{*}{0.007} \\
\hline & 2 & $85.80(4.60)$ & & & \\
\hline & 3 & $101.00(2.35)^{b}$ & & & \\
\hline \multicolumn{6}{|l|}{ Subscale } \\
\hline \multirow[t]{3}{*}{ Family interaction } & 1 & $7.60(1.67)^{\mathrm{a}}$ & \multirow[t]{3}{*}{10.00} & \multirow[t]{3}{*}{2} & \multirow[t]{3}{*}{0.007} \\
\hline & 2 & $21.20(2.17)$ & & & \\
\hline & 3 & $24.40(1.52)^{\mathrm{b}}$ & & & \\
\hline \multirow[t]{3}{*}{ Parenting } & 1 & $8.20(2.28)^{a}$ & \multirow[t]{3}{*}{8.32} & \multirow[t]{3}{*}{2} & \multirow[t]{3}{*}{0.016} \\
\hline & 2 & $22.60(3.44)$ & & & \\
\hline & 3 & $24.20(1.30)^{b}$ & & & \\
\hline \multirow[t]{3}{*}{ Emotional well-being } & 1 & $5.80(2.05)^{a}$ & \multirow[t]{3}{*}{9.58} & \multirow[t]{3}{*}{2} & \multirow[t]{3}{*}{0.008} \\
\hline & 2 & $14.20(1.64)$ & & & \\
\hline & 3 & $16.40(1.52)^{b}$ & & & \\
\hline \multirow[t]{3}{*}{ Physical/Material well-being } & 1 & $8.40(1.14)^{a}$ & \multirow[t]{3}{*}{10} & \multirow[t]{3}{*}{2} & \multirow[t]{3}{*}{0.007} \\
\hline & 2 & $18.20(2.39)$ & & & \\
\hline & 3 & $21.80(2.59)^{b}$ & & & \\
\hline \multirow[t]{3}{*}{ Disability-Related Support } & 1 & $5.00(1.22)^{a}$ & \multirow[t]{3}{*}{8.44} & \multirow[t]{3}{*}{2} & \multirow[t]{3}{*}{0.015} \\
\hline & 2 & $14.60(3.13)$ & & & \\
\hline & 3 & $16.20(2.00)^{b}$ & & & \\
\hline \multirow[t]{3}{*}{ Burden } & 1 & $1.75(0.15)^{\mathrm{a}}$ & \multirow[t]{3}{*}{9.58} & \multirow[t]{3}{*}{2} & \multirow[t]{3}{*}{0.008} \\
\hline & 2 & $0.68(0.18)^{\mathrm{b}}$ & & & \\
\hline & 3 & $0.89(0.18)$ & & & \\
\hline \multicolumn{6}{|l|}{ Subscales } \\
\hline \multirow[t]{3}{*}{ Objective burden } & 1 & $1.71(0.19)^{\mathrm{a}}$ & 10 & 2 & 0.007 \\
\hline & 2 & $0.67(0.21)^{\mathrm{b}}$ & & & \\
\hline & 3 & $0.96(0.13)$ & & & \\
\hline Subjective burden & 1 & $1.85(0.14)^{a}$ & 8.44 & 2 & 0.015 \\
\hline & 2 & $0.70(0.21)^{\mathrm{b}}$ & & & \\
\hline & 3 & $0.75(0.35)$ & & & \\
\hline
\end{tabular}

${ }^{* *} \mathrm{p}$-value $<0.010,{ }^{*} \mathrm{p}$-value $<0.050$

a,ba pair of different characteristics was significantly different ( $\mathrm{p}$-value $<0.050)$

$\mathrm{M}=$ mean, S.D.=standard deviation, $\mathrm{c}^{2}=\mathrm{Chi}-$ square, $\mathrm{df}=$ degrees of freedom

\section{Discussion}

The main purpose of the current study was to determine the feasibility of the family-management intervention, and at the same time examine the initial effectiveness of the intervention to obtain initial signals of improvement in the family quality of life and reduced burden of caregivers of children with autism. Data from the feasibility study of the family-management intervention provided initial evidence that it was a feasible and beneficial intervention for families of children with autism. All participants followed four sessions of the intervention program over four weeks and completed three measurements at three time points. After program completion, the participants provided positive feedback on the intervention.

The result showed that the family-management program, which combined educational sessions and telephone support, resulted in a significant difference in mean score of family quality of life and burden across three point times. The feasibility study showed that families of children with autism in Vietnam could understand and apply the family-management interventions to improve family quality of life and reduce caregiver burden. According 
to literature review and observation, this was one of the very few intervention studies on such families. Especially, intervention programs supporting families both physically and psychology. The result was by supported the FMSF and previous literature..$^{9,10,13,18,19}$ In this study, the PI provided: knowledge of autism (definition of situation); an effective management approach for family caregivers (behaviour management/action); and raised family awareness of having children with autism in the family (the perceived consequences), therefore enhancing family system outcomes, which were specifically defined as family quality of life and burden of caregivers. ${ }^{18,19}$ The intervention sessions strengthened the family's capacity to manage their own lives and their impacted child in order to improve family quality of life and reduce the burden of caregivers. ${ }^{10}$ The familymanagement approaches may encourage focus on family needs including information needs, and emotional support. Participating in the sessions helped the families have the opportunity to learn and share about their experiences in living with children of autism, and to solve problems and challenges, which is also an important factor contributing to the effectiveness of the intervention program. ${ }^{9,10,13}$

The participants evolved through the educational sessions and telephone support. During the educational sessions, many activities were used to improve the total score of family quality of life and the subscale scores of family interaction, emotional wellbeing and physical/ material wellbeing. Group discussions and problem solving based on action plans were conducted within and after the sessions to increase emotional and informational support. Kieckhefer and colleagues ${ }^{10}$ claimed that an educational program strengthened the caregivers' perceptions of the family's capacity in managing a family's daily living. Catalano and colleagues $^{12}$ in a systematic review suggested that educational sessions and support should be integrated to improve not only the psychological well-being of parents, but also influence the wellbeing of children with autism and other family members. The program can help family members cope with and manage their children's behaviours more effectively. Parental interventions have the potential to reduce parents' stress, depression, and anxiety. ${ }^{27}$

The study found that participants not only met at the interventional sessions, they also met or called on the phone at convenient times or while waiting for their autistic child at the unit. As relationships developed, they shared more deeply their feelings, challenges and encouragement, and as a result, their outcome variables improved.

The results of the total and subscales scores of caregiver burden indicate that the caregivers completing the family-management program perceived less burden, both objective and subjective. This finding supported other studies that have examined caregiver burden. ${ }^{10,12,13,18,26,27}$

In fact, there have not been many studies focusing on family-management interventions to reduce the burden of families of children with autism. Da Paz and Wallander ${ }^{28}$ in a narrative review indicated that stress management and relaxation techniques, such as mindfulness-based stress reduction interventions could be utilized to improve parenting stress and general health, and reduce depression and anxiety for parents of children with autism. Moreover, a systematic review of mindfulness interventions reported that the intervention in parents of children with autism effectively reduced stress and increased wellbeing of parents. ${ }^{29}$ In this study, the PI used various teaching/training methods to reduce the burden of the caregivers. To lessen burden, participants observed and practiced self-massage, muscle relaxation, positive self-talk and expression of feelings skills. Moreover, action plans were discussed and set by participants in each educational session. They were asked to share whether their action plan worked, if they faced any challenges in their daily life and were provided with problem solving skills. These activities may lessen the burden of caregivers. Additionally, group discussions and telephone support provided the participants an opportunity to express 
and share their feelings in depth, which provided mutual encouragement from time to time, therefore, reducing subjective burden. Interestingly, the results of this study showed that the mean total score of burden was lower than the burden in the previous studies on autistic children with the same Caregiver's Strain Questionnaire., ${ }^{7,30}$ This may explain that most of the participants in this study were all parents of children about 5 years old, with moderate levels of behavioral problems, therefore, they did not perceive caring for a child with autism as a burden.

The study results revealed that the family quality of life was significantly different after the follow-up period, whereas the burden improved immediately after the intervention. The Caregiver's Strain Questionnaire contained about half of the questions that were subjective in nature, while the Family Quality Of Life Questionnaire mostly included objective questions. ${ }^{22,23}$ In the intervention program, there were various short exercises such as basic meditation, self-massage or some recreational activities that improved participants' emotional problems immediately after the intervention. ${ }^{10}$ In addition, the intervention program emphasized sustainability by training them in the habit of breaking down problems into small goals and action plans. Therefore, domains of family life such as family interaction, parenting, physical/material well-being and disabilityrelated support in the family quality of life may gradually change over longer time. Moreover, the improvements in caregiver burden seem to help enhance family quality of life.

From participant feedback, after completion of the intervention the participants seemed satisfied with the family-management program. Most of the comments from the participants stated they found the discussion sharing time beneficial. They enjoyed sharing their challenges and success strategies and learning from others' experiences. It was found that the family-management program was a safe place for caregivers to share their feelings. Listening to successful strategies from peers had a powerful impact on participants. Such benefits have been found in other family-focused interventions. ${ }^{31-34}$ Additionally, according to FMSF framework, interpersonal relationships is one subconcept of the socio-cultural context, which affects the management of family issues and difficulties of children with chronic illness. ${ }^{19}$

\section{Limitations}

The study collected data at only one setting with a sample size of 5 non-randomized participants, leading to considerable bias in the research results. This was a feasibility study without a control group, therefore, it may not be concluded that the improvement in the study variables came from the intervention program. Furthermore, the PI was the person who directly recruited the participants, implemented the intervention program, and interviewed to collect data after participants' received the intervention, which caused potential bias in the research results. The pretest-posttest one-group design with only 5 participants may not provide adequate representation of all family caregivers of children with autism.

\section{Recommendations and implications for nursing}

\section{practice}

The study results suggested that family-management intervention could feasibly be used in families of children with autism. Healthcare workers, especially nurses, should consider this intervention as an integral component of the usual care activities for families and children with autism. This feasibility study may not be conclusive on the effectiveness of the intervention program. However, nurses should be trained to understand the roles of the components in the intervention program. Problem-solving group discussion sessions based on action plans and 
phone support may help family caregivers improve their challenging issues while living with an autistic child. Future randomized controlled trial studies with a larger sample size should be performed. Moreover, extension of duration of follow-up could be used to determine the sustainability of family caregiver management.

\section{Conclusion}

The overall increase in family quality of life and decrease in caregiver burden total and subscales' scores suggest that the material from the family management program was successfully communicated to the majority of caregivers of children with autism. The greatest benefits to parents were shown by the improvement in the scores of outcome variables and their satisfaction with the intervention program, which indicated that the familymanagement intervention was acceptable and feasible for family caregivers of children with autism. Future studies of the family-management intervention should explore the effectiveness of this intervention with randomised controlled trials using a larger sample size.

\section{Acknowledgement}

The authors thank all participants who greatly contributed to this study and all staff at the National hospital in Hanoi, Vietnam for their contribution.

\section{Funding sources}

The authors thank Vietnam Ministry of Education and Training, Nam Dinh University of Nursing (Vietnam) and Burapha University Graduate School (Thailand) for financial support to carry out this study.

\section{Conflict of interest}

The authors declare that there is no conflict of interest.

\section{References}

1. Matthew J, Kelly A, Baio J, Wiggins L, Christensen DL, Maenner MJ, et al. Prevalence of autism spectrum disorder among children aged 8 years - autism and developmental disabilities monitoring network, 11 sites, United States, 2016. MMWR Surveill Summ 2020;69:1-12.

2. Hoang $M$, Le V, Chu Q, Le N, Duong D, Thanh M, et al. Prevalence of autism spectrum disorders and their relation to selected socio-demographic factors among children aged 18-30 months in northern Vietnam, 2017. Int J Ment Health Syst 2019;13:29.

3. VTC NEWS. Ministry of Labor, Invalids and Social Affairs of Vietnam. Alarming: Vietnam has more than 200,000 autistic children 2014 [homepage on the Internet]. Hanoi: VTC NEWS; 2017 [cited 2014 Apr 11]. Available from: https://vtc.vn/dangbao-dong-viet-nam-co-hon-200000-tre-tu-ky-ar315020. $\mathrm{html}$

4. Fitzpatrick SE, Srivorakiat L, Wink LK, Pedapati EV, Erickson CA. Aggression in autism spectrum disorder: presentation and treatment options. Neuropsychiatr Dis Treat 2016;12:152538.

5. Hill AP, Zuckerman KE, Hagen AD, Kriz DJ, Duvall SW, van Santen J, et al. Aggressive behavior problems in children with autism spectrum disorders: prevalence and correlates in a large clinical sample. Res Autism Spectr Disord 2014;8:1121-33.

6. Fitzpatrick SE, Srivorakiat L, Wink LK, Pedapati EV, Erickson CA. Aggression in autism spectrum disorder: presentation and treatment options. Neuropsychiatr Dis Treat 2016;12: 1525-38

7. Mai TLA. Factors related to burden among caregivers of children with autism in Vietnam [Unpublishe master thesis]. Chon Buri: Burapha University; 2015.

8. Jones S, Bremer E, Lloyd M. Autism spectrum disorder: family quality of life while waiting for intervention services. Qual Life Res 2017;26:331-42.

9. Ji B, Sun M, Yi R, Tang S. Multidisciplinary parent education for caregivers of children with autism spectrum disorders. Arch Psychiatr Nurs 2014;28:319-26.

10. Kieckhefer GM, Trahms CM, Churchill SS, Kratz L, Uding N, Villareale N. A randomized clinical trial of the Building on Family Strengths program: an education program for parents of children with chronic health conditions. Matern Child Health J 2014;18:563-74. 
11. Bekhet AK. Positive thinking training intervention for caregivers of persons with autism: establishing fidelity. Arch Psychiatr Nurs 2017;31:306-10.

12. Catalano D, Holloway L, Mpofu E. Mental health interventions for parent carers of children with autistic spectrum disorder: Practice guidelines from a critical interpretive synthesis (cis) systematic review. Int J Environ Res Public Health 2018;15:341.

13. de Bruin El, Blom R, Smit FM, van Steensel FJ, Bögels SM. MYmind: mindfulness training for youngsters with autism spectrum disorders and their parents. Autism 2015;19:90614.

14. Clifford T, Minnes P. Logging on: evaluating an online support group for parents of children with autism spectrum disorders. J Autism Dev Disord 2013;43:1662-75.

15. Ferdig RE, Pytash KE. Technology and emotion: Playing for the love of the game. Well Played 2012;1:1-22.

16. Van Stolk C, Hofman J, Hafner M, Janta B. Psychological wellbeing and work: improving service provision and outcomes. Rand Health Q 2014;4:9.

17. Hoang VM, Le TV, Chu TTQ, Le BN, Duong MD, Thanh NM, et al. Prevalence of autism spectrum disorders and their relation to selected socio-demographic factors among children aged 18-30 months in northern Vietnam, 2017. Int $\mathrm{J}$ Ment Health Syst 2019;3:29.

18. Knafl K, Deatrick JA, Gallo AM. The interplay of concepts, data, and methods in the development of the Family Management Style Framework. J Fam Nurs 2008;14:412-28.

19. Knafl KA, Deatrick JA, Knafl GJ, Gallo AM, Grey M, Dixon J. Patterns of family management of childhood chronic conditions and their relationship to child and family functioning. J Pediatr Nurs 2013;28:523-35.

20. Gray, JR, Grove, SK, Sutherland, S. Burns and Grove's the practice of nursing research: appraisal, synthesis, and generation of evidence. $8^{\text {th }}$ ed. St. Louis, MO: Elsevier; 2017; p.508.

21. Gaugler JE, Davey A, Pearlin LI, Zarit SH. Modeling caregiver adaptation over time: the longitudinal impact of behavior problems. Psychol Aging 2000;15:437-50.

22. Hoffman L, Marquis J, Poston D, Summers J A, Turnbull A. Assessing family outcomes: psychometric evaluation of the Beach Center Family Quality of Life Scale. J Marriage Fam 2006;68:1069-83.
23. Brannan AM, Heflinger CA, Bickman L. The Caregiver Strain Questionnaire: measuring the impact on the family of living with a child with serious emotional disturbance. J Emot Behav Disord 1997;5:212-22.

24. World Health Organization. Process of translation and adaptation of instruments 2016 [homepage on the Internet]. Geneva: WHO; 2016 [cited 2020 Apr 30]. Available from: http://www. who.int/substance_abuse/research_tools/translation/en/

25. Waltz CF, Strickland O, Lenz ER. Measurement in nursing and health research. $5^{\text {th }}$ ed. New York: Springer; 2017;p.188-9.

26. McStay RL, Trembath D, Dissanayake C. Stress and family quality of life in parents of children with autism spectrum disorder: parent gender and the double ABCX model. J Autism Dev Disord 2014;44:3101-18.

27. Hsiao YJ, Higgins K, Pierce T, Whitby PJS, Tandy RD. Parental stress, family quality of life, and family-teacher partnerships: families of children with autism spectrum disorder. Res Dev Disabil 2017;70:152-62.

28. Da Paz NS, Wallander JL. Interventions that target improvements in mental health for parents of children with autism spectrum disorders: a narrative review. Clin Psychol Rev 2017;51:1-14.

29. Cachia RL, Anderson A, Moore DW. Mindfulness, stress and well-being in parents of children with autism spectrum disorder: a systematic review. J Child Fam stud 2016;25:1-14.

30. Khanna R, Madhavan SS, Smith MJ, Tworek C, Patrick JH, Becker-Cottrill B. Psychometric properties of the Caregiver Strain Questionnaire (CGSQ) among caregivers of children with autism. Autism 2012;16:179-99.

31. Estes A, Swain DM, MacDuffie KE. The effects of early autism intervention on parents and family adaptive functioning. Pediatr Med 2019;2:21.

32. Bayoumi M, Ezzat O, Samarkandi O. Quality of life and subjective burden on family caregiver of children with autism. Am J Nurs Sci 2017;33:33-9.

33. Kuhaneck HM, Madonna S, Novak A, Pearson E. Effectiveness of interventions for children with autism spectrum disorder and their parents: A systematic review of family outcomes. Am J Occup Ther 2015;69:1-14.

34. Hoefman R, Payakachat N, van Exel J, Kuhlthau K, Kovacs E, Pyne J, et al. Caring for a child with autism spectrum disorder and parents' quality of life: application of the CarerQol. J Autism Dev Disord 2014;44:1933-45. 